\title{
Paradoxical Hypoxemia with Simultaneous Use of Pulmonary Vasodilators in a Case of PPHN
}

\section{Journal of \\ Pediatrics \& Child Care}

\begin{abstract}
Persistent pulmonary hypertension of the newborn (PPHN) is characterized by the persistence of high pulmonary vascular resistance (PVR) of fetal life, after birth. Inhaled nitric oxide (iNO) has been the mainstay of PPHN treatment. Intravenous (IV) sildenafi and inhaled epoprostenol are newer agents, which are currently not FDA approved. We describe the first reported case of PPHN in which the simultaneous use of iNO, IV sildenafil and inhaled epoprosteno resulted in hypotension and paradoxical hypoxemia. Term infant with PPHN of unknown etiology was treated with iNO with inadequate clinical response. Inhaled epoprostenol was added on day 4 of life to achieve synergism to iNO action. IV sildenafil was added to minimize rebound pulmonary hypertension associated with iNO withdrawal. However, within minutes of its administration a paradoxical response was noticed with significant hypotension and hypoxemia. IV sildenafil was immediately discontinued. We discuss the mechanism of action of each pharmacological agent and the resultant interactions that led to adverse effects in this patient.
\end{abstract}

\section{Introduction}

PPHN is a complex disease of the newborn, characterized by the persistence of high PVR of fetal life, after birth. This leads to a right to left shunting of blood through the patent ductus arteriosus (PDA) and the patent foramen ovale (PFO), leading to poor oxygenation of blood. The most accepted pathophysiology responsible for PPHN is the imbalance between pulmonary vasodilators, such as nitric oxide $(\mathrm{NO})$ and prostacyclins ( $\mathrm{PGI}_{2}$ ), and vasoconstrictors, such as endothelin-1 and thromboxane $A_{2}[1,2]$.

Since its FDA approval in 1999, iNO has been the mainstay of PPHN treatment $[3,4]$. It acts by stimulating soluble guanylate cyclase (sGC) in pulmonary vascular smooth muscle cells, thereby increasing the production of cyclic guanosine monophosphate (cGMP) [5]. cGMP stimulates calcium efflux from pulmonary vascular smooth muscle cells. This leads to pulmonary vasodilation without causing systemic vasodilation [5].

Inhaled prostacyclin has emerged as a novel agent used in the treatment of PPHN especially useful in cases resistant to conventional iNO therapy. Studies have proven its effectiveness and safety when used alone [6,7]. Inhaled prostacyclin, such as epoprostenol, act synergistically with $\mathrm{NO}$, to achieve pulmonary arterial smooth muscle relaxation by the cyclic adenosine monophosphate (cAMP) pathway and act as adjuncts in the treatment of PPHN [6]. Prostacyclins bind to their receptor on smooth muscle cell and stimulate adenylate cyclase (AC) to increase production of cAMP [6]. This, in turn increases calcium efflux from pulmonary vascular smooth muscle cells leading to vasodilation.

More recently, Phosphodiesterase-5 (PDE-5) inhibitors, such as sildenafil, have been used in infants to achieve better oxygenation as
Vidit Bhargava', Clarissa DeLeon ${ }^{2}$, Shreyas Arya ${ }^{1}$ and Sunil K. Jain ${ }^{2}$

${ }^{\prime}$ Department of Pediatrics, University of Texas Medical Branch, Galveston, TX, USA

${ }^{2}$ Department of Pediatrics/Division of Neonatology, University of Texas Medical Branch, Galveston, TX, USA

*Address for Correspondence:

Sunil K. Jain, MD, FAAP, Professor of Pediatrics and Obstetrics, Department of Pediatrics/Division of Neonatology, University of

Texas Medical Branch, 301 University Blvd, 6.104 Waverley Smith Pavilion, Galveston, TX 77555-0526, USA, Tel: 409-772-2815; Fax: 409-772-0747; E-mail: skjain@utmb.edu

Submission: 09 November, 2015

Accepted: 15 December, 2015

Published: 21 December, 2015

Copyright: @ 2015 Bhargava V. This is an open access article distributed under the Creative Commons Attribution License, which permits unrestricted use, distribution, and reproduction in any medium, provided the original work is properly cited.

monotherapy and in combination with iNO [7]. Sildenafil inhibits PDE-5 induced degradation of cGMP [8]. This further augments the pulmonary vasodilation action of iNO (Figure 1). Sildenafil has also shown to minimize the rebound pulmonary hypertension seen with iNO withdrawal in neonates [9].

\section{Case}

The patient is a term infant with echocardiographic diagnosis of PPHN of unknown etiology. Initial echocardiography demonstrated a normal 4-chamber anatomy, super systemic right sided pressures (peak systolic gradient across tricuspid valve $55 \mathrm{mmHg}$ ) and bidirectional shunting at the level of PDA and PFO. The diagnosis was further supported by hypoxemia out of proportion to the

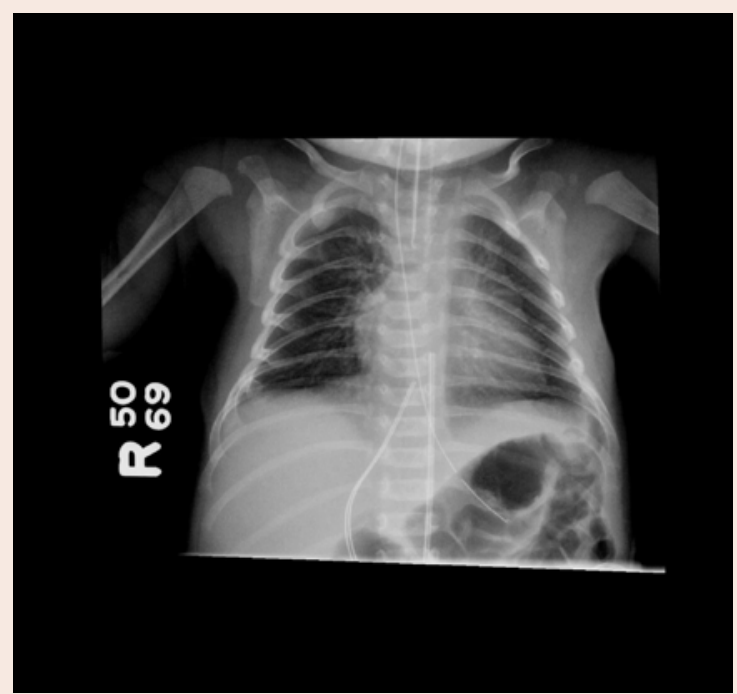

Figure 1: Chest radiograph depicting relative lack of parenchymal changes and lung field oligemia suggestive of PPHN. 

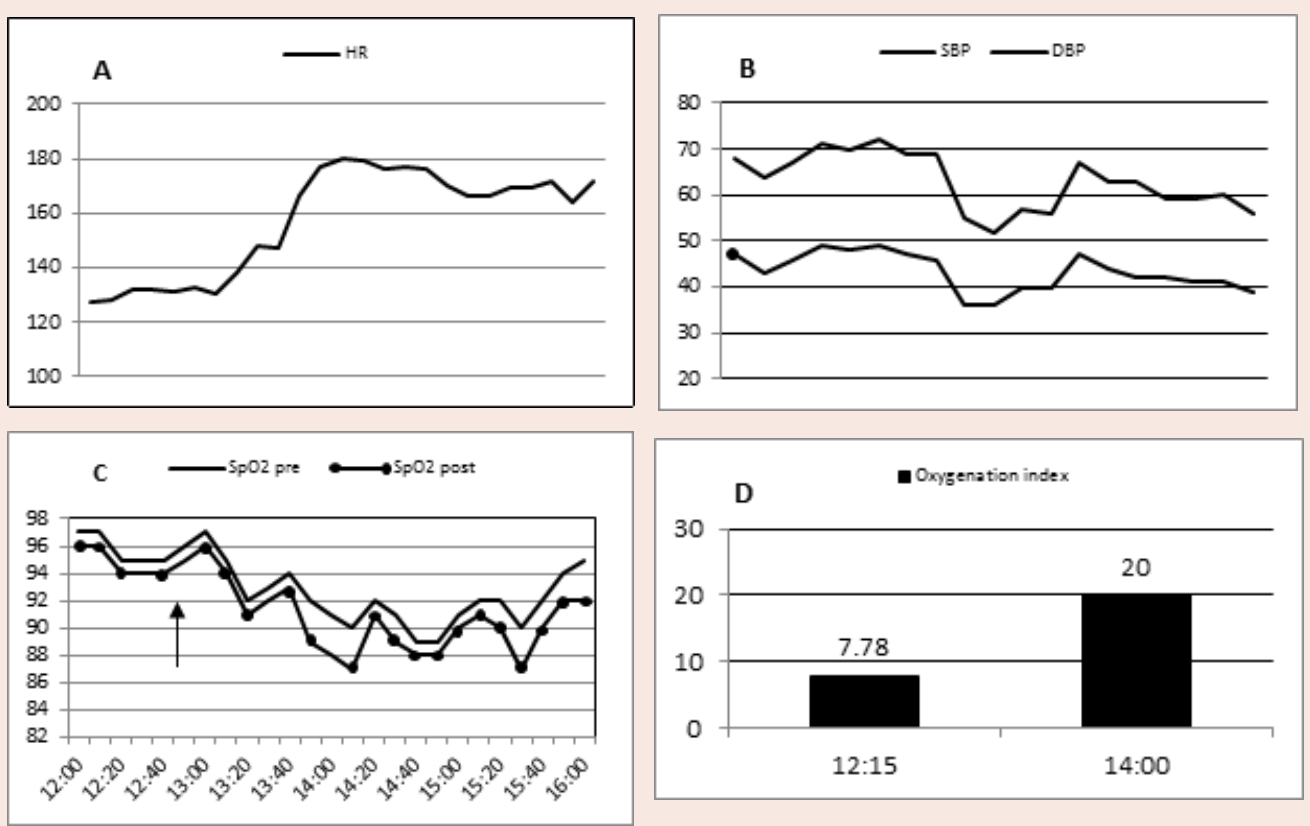

Figure 2: Graph depicting changes in vitals with IV sildenafil use. Administration of IV sildenafil is represented by arrow. A) Rise in heart rate (HR), B) Drop in systolic blood pressure (SBP) and diastolic blood pressure (DBP), C) Drop in pre and postductal saturation (SpO2) and D) Changes in Ol with administration of IV sildenafil.

parenchymal changes on chest radiography (Figure 1); arterial blood gas (ABG) showing $\mathrm{PaO}_{2} 42 \mathrm{mmHg}$ (NL: 52-93 $\mathrm{mmHg}$ ), $\mathrm{PaCO}_{2}$ $38 \mathrm{mmHg}$ (NL: $25-42 \mathrm{mmHg}$ ), bicarbonate $21 \mathrm{mEq} / \mathrm{L}$ (NL: 14-24 $\mathrm{mEq} / \mathrm{L}$ ) and $\mathrm{pH} 7.37$ (NL: 7.35-7.45), oxygenation index (OI) 38 and greater than $10 \%$ difference in preductal $(97 \%)$ and postductal $(86 \%)$ oxygen saturations $\left(\mathrm{SpO}_{2}\right)$.

The patient was started on conventional mechanical ventilation and IV sedation with fentanyl at $1 \mathrm{mg} / \mathrm{kg} / \mathrm{hr}$ and midazolam at 0.2 $\mathrm{mg} / \mathrm{kg} / \mathrm{hr}$. iNO was started at $20 \mathrm{ppm}$. Vasopressors (dopamine, dobutamine and epinephrine) were added and titrated as needed to maintain systolic blood pressures above right sided pressure. In the absence of adequate response defined as persistent severe hypoxemia (minimal change in OI), inhaled epoprostenol was added on day 4 of life at $0.05 \mathrm{mcg} / \mathrm{kg} / \mathrm{min}$ and was titrated up by $0.01 \mathrm{mcg} / \mathrm{kg} /$ min every 30 minutes as tolerated to a max of $0.1 \mathrm{mcg} / \mathrm{kg} / \mathrm{min}$. The patient showed a good response to treatment, with improvements in preductal (99\%) and postductal (98\%) oxygen saturations $\left(\mathrm{SaO}_{2}\right)$, stabilization of systemic blood pressures and a lower OI (7.78) based on ABG. By day 7 of life, slow wean of pressors and iNO was started.

On day 7, at iNO of 5 ppm, IV sildenafil was started to attenuate rebound pulmonary hypertension associated with iNO withdrawal in neonates. A loading dose of $0.5 \mathrm{mg} / \mathrm{kg}$ was administered over 30 minutes, and within minutes a paradoxical response was noted with significant systemic hypotension (blood pressure dropped from $73 / 51$ to $50 / 35 \mathrm{~mm}$ of $\mathrm{Hg}$ ), hypoxemia (pre-ductal $\mathrm{SaO}_{2} 89 \%$; post ductal $\left.\mathrm{SaO}_{2} 86 \%\right)$ and tachycardia with substantial increase in OI to 20 (Figure 2). Sildenafil was immediately discontinued, iNO was increased from 5 to $20 \mathrm{ppm}$, and pressor support was increased with the subsequent normalization of oxygenation (preductal saturation 99\%; post ductal saturation $98 \%$ ) and blood pressures (73/48 $\mathrm{mmHg}$ ).
Subsequently, infant was weaned off iNO, epoprostenol and pressors; gradually and as tolerated without any further complications. He continued to do well till discharge home.

\section{Discussion}

The individual roles of iNO, systemic sildenafil and inhaled epoprostenol are well established in improving oxygenation and PVR in cases of PPHN $[4,6,7]$. However, as shown above in our patient, the concomitant use of iNO, inhaled epoprostenol and sildenafil resulted in paradoxical hypotension and hypoxemia. Shekerdemian et al. studied the interaction of iNO and IV sildenafil on a porcine model of PPHN secondary to meconium aspiration [10]. They observed that the simultaneous use of iNO and IV sildenafil resulted in lowered systemic blood pressure and systemic vascular resistance and produced profound arterial hypoxemia consistent with the effects seen in our patient. In this study, a $14 \%$ drop in mean arterial pressure was noted $(70 \mathrm{mmHg}$ to $60 \mathrm{mmHg}$ ), compared to our patient in whom an $18 \%$ drop was noted ( $55 \mathrm{mmHg}$ to $45 \mathrm{mmHg}$ ).

Steinhorn et al. studied the pharmacokinetics of IV sildenafil use along with iNO. They noted that when IV sildenafil was administered in a loading dose of $0.05 \mathrm{mg} / \mathrm{kg}$ over 30 minutes or longer, it was well tolerated [7]. In their study, even higher loading doses were well tolerated when administered over 3 hours. However, any loading dose administered over less than 30 minutes resulted in hypotension. In our patient, hypotension and hypoxemia were noticed even though sildenafil was administered over 30 minutes. We propose this as the underlying mechanism for the changes seen in our patient upon administering IV sildenafil along with iNO and epoprostenol.

$\mathrm{NO}$ and sildenafil mediate calcium efflux out of vascular smooth muscle cell via the cGMP pathway [11]. Epoprostenol performs the same action via the cAMP pathway [12], thus further potentiating the 
Citation: Bhargava V, DeLeon C, Arya S, Jain SK. Paradoxical Hypoxemia with Simultaneous Use of Pulmonary Vasodilators in a Case of PPHN. J Pediatr Child Care. 2015;1(2): 3.

ISSN: 2380-0534

pulmonary vasodilator effect of NO. Sildenafil and epoprostenol also mediate systemic vasodilation. This can lead to systemic hypotension, increased right to left shunting across PFO and PDA and subsequent hypoxemia. In addition, iNO and epoprostenol are selectively distributed to well-ventilated areas to achieve localized pulmonary vasodilation. Sildenafil achieves pulmonary vasodilation in well and poorly ventilated areas of lung, leading to improved perfusion in these areas $[13,14]$. This results in an exacerbation of ventilation perfusion (V-Q) mismatch in these poorly ventilated areas of the lung $[13,14]$. We propose this as the underlying mechanism for the changes seen in our patient upon administering IV sildenafil along with iNO and epoprostenol.

\section{Conclusion}

Sildenafil and epoprostenol are newer agents that are especially useful in cases of PPHN resistant to conventional iNO therapy. These agents are currently not FDA approved for PPHN. Studies have proven their effectiveness and safety when used alone. However, their simultaneous use has not been studied extensively thus far. As such, extreme clinical caution is warranted when using these agents together. We propose administration of IV sildenafil over 3 hours as the safest approach in order to minimize paradoxical hypotension and hypoxemia particularly when used in combination with iNO and epoprostenol. In addition, titrating the dose of epoprostenol with the addition of sildenafil should be considered.

\section{References}

1. Abman SH (1994) Pathogenesis and treatment of neonatal and postnatal pulmonary hypertension. Curr Opin Pediatr 6: 239-247.

2. Kinsella JP, Abman SH (1995) Recent developments in the pathophysiology and treatment of persistent pulmonary hypertension of the newborn. J Pediatr 126: 853-864.

3. Davidson D, Barefield ES, Kattwinkel J, Dudell G, Damask M, et al.
(1998) Inhaled nitric oxide for the early treatment of persistent pulmonary hypertension of the term newborn: a randomized, double-masked, placebocontrolled, dose-response, multicenter study. The I-NO/PPHN Study Group. Pediatrics 101(3 Pt 1): 325-334.

4. Cornfield DN, Maynard RC, deRegnier RA, Guiang SF 3rd, Barbato JE, et al. (1999) Randomized, controlled trial of low-dose inhaled nitric oxide in the treatment of term and near-term infants with respiratory failure and pulmonary hypertension. Pediatrics 104(5 Pt 1): 1089-1094

5. Deruelle P, Grover TR, Abman SH (2005) Pulmonary vascular effects of nitric oxide-cGMP augmentation in a model of chronic pulmonary hypertension in fetal and neonatal sheep. Am J Physiol Lung Cell Mol Physiol 289: L798-L806.

6. Kelly LK, Porta NF, Goodman DM, Carroll CL, Steinhorn RH (2002) Inhaled prostacyclin for term infants with persistent pulmonary hypertension refractory to inhaled nitric oxide. J Pediatr 141: 830-832.

7. Steinhorn RH, Kinsella JP, Pierce C, Butrous G, Dilleen M, et al. (2009) Intravenous sildenafil in the treatment of neonates with persistent pulmonary hypertension. J Pediatr 155: 841-847.e1.

8. Moreno L, Losada B, Cogolludo Al, Lodi F, Lugnier C, et al. (2004) Postnatal maturation of phosphodiesterase 5 (PDE5) in piglet pulmonary arteries: activity, expression, effects of PDE5 inhibitors, and role of the nitric oxide/ cyclic GMP pathway. Pediatr Res 56: 563-570.

9. Atz AM, Wessel DL (1999) Sildenafil ameliorates effects of inhaled nitric oxide withdrawal. Anesthesiology 91: 307-310.

10. Shekerdemian LS, Ravn HB, Penny DJ (2004) Interaction between inhaled nitric oxide and intravenous sildenafil in a porcine model of meconium aspiration syndrome. Pediatr Res 55: 413-418.

11. Wang C, Wang J, Zhao L, Wang Y, Liu J, et al. (2008) Sildenafil inhibits human pulmonary artery smooth muscle cell proliferation by decreasing capacitative Ca2+ entry. J Pharmacol Sci 108: 71-78.

12. Holzmann S, Kukovetz WR, Schmidt K (1980) Mode of action of coronary arterial relaxation by prostacyclin. J Cyclic Nucleotide Res 6: 451-460.

13. Clark RH, Kueser TJ, Walker MW, Southgate WM, Huckaby JL, et al. (2000) Low-dose nitric oxide therapy for persistent pulmonary hypertension of the newborn. Clinical Inhaled Nitric Oxide Research Group. N Engl J Med 342: 469-474.

14. Dukarm RC, Russell JA, Morin FC 3rd, Perry BJ, Steinhorn RH (1999) The cGMP-specific phosphodiesterase inhibitor E4021 dilates the pulmonary circulation. Am J Respir Crit Care Med 160: 858-865. 